\title{
applied optics
}

\section{Semiquantitative analysis of mercury in landfill leachates using double-pulse laser-induced breakdown spectroscopy}

\author{
Carlos R. Menegatti, ${ }^{1}$ Gustavo Nicolodelli, ${ }^{2}$ Giorgio S. Senesi, ${ }^{3}$ Otavio A. da Silva, ${ }^{1}$ \\ Hélcio J. I. Filho, ${ }^{1}$ Paulino R. Villas Boas, ${ }^{2}$ Bruno S. Marangoni, ${ }^{4}$ and Débora M. B. P. Milori ${ }^{2, *}$ \\ ${ }^{1}$ School of Engineering of Lorena, São Paulo University, P.O. Box 116, Lorena, São Paulo 12602-810, Brazil \\ ${ }^{2}$ Embrapa Instrumentation, São Carlos, SP BR-13560970, Brazil \\ ${ }^{3}$ CNR, Istituto di Nanotecnologia (NANOTEC), PLasMI Lab, Via Amendola 122/D, 70126 Bari, Italy \\ ${ }^{4}$ Physics Institute, Federal University of Mato Grosso do Sul, P.O. Box 549, Campo Grande, MS 79070-900, Brazil \\ *Corresponding author: debora.milori@embrapa.br
}

Received 10 February 2017; revised 22 March 2017; accepted 24 March 2017; posted 24 March 2017 (Doc. ID 286577 ); published 24 April 2017

\begin{abstract}
Laser-induced breakdown spectroscopy (LIBS) is showing to be a promising, quick, accurate, and practical technique to detect and measure metal contaminants and nutrients in urban wastes and landfill leachates. Although conventional LIBS presents some limitations, such as low sensitivity, when used in the single pulse configuration if compared to other spectroscopic techniques, the use of the double-pulse (DP) configuration represents an adequate alternative. In this work DP LIBS has been applied to the qualitative and quantitative analysis of mercury $(\mathrm{Hg})$ in landfill leachates. The correlation analysis performed between each intensified charge-coupled device pixel and the $\mathrm{Hg}$ concentration allowed us to choose the most appropriate $\mathrm{Hg}$ emission line to be used for its measure. The normalization process applied to LIBS spectra to correct physical matrix effects and small fluctuations increased from 0.82 to 0.98 the linear correlation of the calibration curve between LIBS and the reference data. The limit of detection for $\mathrm{Hg}$ estimated using DP LIBS was $76 \mathrm{mg} \mathrm{Kg}^{-1}$. The cross validation (leave-oneout) analysis yielded an absolute average error of about $21 \%$. These values showed that the calibration models were close to the optimization limit and satisfactory for $\mathbf{H g}$ quantification in landfill leachate. () 2017 Optical Society of America
\end{abstract}

OCIS codes: (300.6365) Spectroscopy, laser induced breakdown; (300.2140) Emission.

https://doi.org/10.1364/AO.56.003730

\section{INTRODUCTION}

The issue of urban waste disposal is a major environmental concern faced by modern society. With the intensification of industrial processes combined with population growth and the consequent demand of consumer goods, large quantities of waste are produced, which in most cases are addressed to landfills. In landfills, wastes undergo physical, chemical, and biological decomposition producing gaseous and liquid waste fractions. In particular, the liquid fraction, that is, the leachate [1] resulting from waste decomposition combined with rainfall, is affected by landfill temperature and the composition of the waste deposited. The action of bacteria accelerates the decomposition of waste, while percolating rainwater carries the degradation products to the lower layer of the embankment. The landfill percolate has a variable chemical composition containing large amounts of organic matter and various heavy metals $[2,3]$, thus making it very dangerous for the surrounding environment. The landfill flow may contaminate the underlying soil and also closer water bodies. Thus, monitoring landfill leachate for the presence and concentration of contaminants is crucial in order to take necessary precautions and apply appropriate treatment measures.

One of the most toxic and hazardous element that may be found in landfill leachate is mercury $(\mathrm{Hg})$, which can be present in three forms: elemental or metallic, inorganic, and organic [4]. The concentration of $\mathrm{Hg}$ in municipal waste landfill leachates is evaluated to fall in the range from 0.05 to $160 \mu \mathrm{g} / \mathrm{l}$ $[5,6,7]$. Currently, the analytical techniques available to determine the concentration of metal contaminants, such as $\mathrm{Hg}$, in landfill leachates include atomic absorption spectroscopy, $x$-ray fluorescence, inductively coupled plasma atomic emission spectroscopy (ICP-AES), and inductively coupled plasma mass spectrometry $[8,9]$. Although these techniques are precise and have good limits of detection (LOD) [10], they are relatively time consuming and generate waste. Further, these techniques require a very accurate sample preparation that makes 
the whole process very laborious, thus resulting in the impossibility to measure real-time, in situ metal contaminants in the leachate.

Laser-induced breakdown spectroscopy (LIBS) is a robust, reliable, and simple alternative analytical technique that has been adapted and improved in the years to analyze solid, liquid, aerosol, and gaseous materials in various experimental conditions and is also by, portable instruments, suitable for real-time, on-site analysis [11]. LIBS has been applied in several fields, including the determination of heavy metals in agrienvironmental samples like soils and fertilizers [12-16], remote analysis [17], analysis of hazardous materials, and the composition of Mars surface [18].

In particular, in recent years, some improvements have been made for $\mathrm{Hg}$ determination by single-pulse (SP) LIBS in solid, liquid, and vapor samples. For example, Srungaram et al. [19] used a conventional LIBS apparatus operating at the fundamental wavelength of $1064 \mathrm{~nm}$ for $\mathrm{Hg}$ analysis in soils with a LOD of $483 \mathrm{mg} \mathrm{Kg}^{-1}$. Sobral et al. [20] obtained a LOD of 21.4 and $3.7 \mathrm{mg} \mathrm{Kg}^{-1}$ for $\mathrm{Hg}$ in water and ice samples, respectively. Fang and Ahmad [21] obtained a LOD on the order of $85 \mathrm{mg} \mathrm{Kg}^{-1}$ when analyzing the surface of a water sample. Recently, Zheng et al. [22] obtained a LOD of $0.36 \mathrm{mg} \mathrm{Kg}^{-1}$ for $\mathrm{Hg}$ in aqueous solutions. As a result of these works, it appears that the LOD of $\mathrm{Hg}$ obtained by LIBS, especially in solid samples, still needs to be improved. Although LIBS presents some limitations if compared to other spectroscopic techniques [23], such as low sensitivity, the use of double-pulse (DP) LIBS, as an alternative to SP LIBS, has been shown to improve the analytical performance of LIBS [16].

In this work the DP LIBS technique was applied for semiquantitative analysis in landfill leachate samples doped with $\mathrm{HgSO}_{4}$, simulating highly contaminated environmental samples. A correlation analysis and a normalization procedure were performed to assist in the choice of an appropriate $\mathrm{Hg}$ emission line and to develop a feasible quantification model. The ionic emission line $\mathrm{Hg}$ II $(194.163 \mathrm{~nm})$ was analyzed as an alternative for the conventional atomic emission line $\mathrm{Hg}$ I $(253.65 \mathrm{~nm})$ interfered by $\mathrm{Fe} \mathrm{I}(253.56 \mathrm{~nm})$ and Fe II $(253.66 \mathrm{~nm})$ emission lines in these samples. To the best of our knowledge, no papers have been published in the scientific literature on the application of DP LIBS to the determination of $\mathrm{Hg}$ LOD in landfill leachates.

\section{EXPERIMENTAL PART}

\section{A. Sample Preparation}

The leachate sample was collected in the landfill of Cachoeira Paulista, São Paulo, Brazil, and subjected to a distillation process to obtain a semisolid residue. Generally, the distillation or evaporation process can be used as an alternative technique for the treatment of leachates. The purpose of these techniques is to separate the leachate solution into a nonvolatile solute (concentrate) and a volatile solvent (water vapor and $\mathrm{N}-\mathrm{NH}_{3}$ fractions). Solid compounds and metals are concentrated after distillation. The semisolid residue was then dried in an oven at $120^{\circ} \mathrm{C}$. The overall process reduces the mass of residual liquid to approximately $2 \%$ of the initial value, thereby increasing by 50 times the concentration of the sample. Once we have obtained this solid residue, an ICP-AES analysis of $\mathrm{Hg}$ was performed, which yielded an $\mathrm{Hg}$ concentration lower than the limit of quantification of the equipment, which is approximately $1 \times 10^{-4} \mathrm{mg} \mathrm{kg}^{-1}$. Thus, the original solid sample was mixed with appropriate amounts of $\mathrm{HgSO}_{4}$ to obtain 10 samples with an $\mathrm{Hg}$ concentration ranging from 50 to $1000 \mathrm{mg} \mathrm{Kg}^{-1}$. After homogenization in a mortar, two pellets were prepared for each sample by pressing the powders at 8 ton for $30 \mathrm{~s}$. The pellets were then heated for $1 \mathrm{~h}$ at $60^{\circ} \mathrm{C}$ to remove excessive moisture and ensure that they were completely dried.

\section{B. DP LIBS Experimental Setup}

The LIBS system used was composed by two Nd:YAG lasers operating at wavelengths of either $1064 \mathrm{~nm}$ (IR) or $532 \mathrm{~nm}$ (VIS). In particular, a $Q$-switched Nd:YAG laser (Quantel, Ultra) with a pulse duration of $6 \mathrm{~ns}$, a repetition rate of $20 \mathrm{~Hz}$, and a maximum pulse energy of $75 \mathrm{~mJ}$ was used to generate the IR pulse (Fig. 1). Another $Q$-switched $\mathrm{Nd}$ : YAG laser (Quantel, Brillant), coupled with a second harmonic generator module, with a pulse duration of $4 \mathrm{~ns}$, a repetition rate of $20 \mathrm{~Hz}$, and a maximum pulse energy of $180 \mathrm{~mJ}$, was used to generate the VIS pulse. A 400-Butterfly Aryelle system was used to detect and select the wavelengths. The spectrometer operated in two spectral bands, $175-330$ and $275-750 \mathrm{~nm}$, with a spectral resolution of $13-24$ and 29-80 pm, respectively, and was provided with an intensified charge-coupled device camera with $1024 \times 1024$ pixels.

Two laser beams with a total power density (laser VIS + laser IR) of approximately $2.0 \times 10^{12} \mathrm{Wcm}^{-2}$ were used for the acquisition of DP LIBS spectra in the collinear geometry configuration. The beams were focused and aligned by dichroic mirrors to hit the target sample in the overlapping mode with a delay between them. To optimize the signal-to-noise ratio, the variations of delay time and interpulse delay (from 300 to $1000 \mathrm{~ns}$ ) were investigated preliminarily by performing 10 measurements for each configuration at different positions on the surface of each sample. The best performing values obtained from five accumulated pulses were an interpulse delay of $800 \mathrm{~ns}$ and a delay time of $1 \mu \mathrm{s}$ with a width gate of $10 \mu \mathrm{s}$. To get an efficient collection of emitted plasma, two silica lenses used at the optical position were placed between the sample and the tip of the fiber. The sample support was placed in a microcontrolled $x-y$ stage for an easy and fast scanning of the laser beam impinging on it. The LIBS spectral background was

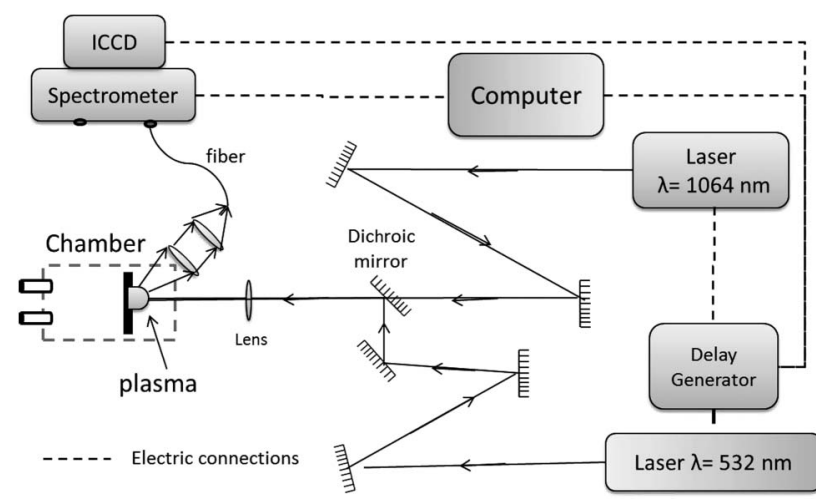

Fig. 1. Schematic diagram of the experimental setup. 
corrected by subtracting the average noise region near the element emission line. Results were based on the averaged areas obtained from the Gaussian fit for one peak emission in each spectrum.

\section{Spectral Processing}

A correlation analysis approach was implemented to identify the emission lines, that is, for each sample a specific pixel was selected in the averaged spectrum, and a Pearson's linear correlation between the pixel intensity and the $\mathrm{Hg}$ concentration was determined [13]. Thus, if the pixel intensity increases as the $\mathrm{Hg}$ concentration in the sample increases, the correlation number results are positive. The closer to 1 the correlation results, the greater the chances for an $\mathrm{Hg}$ electronic emission line to be in that spectral region. By performing the analysis for all pixels in the spectrum, the regions containing the $\mathrm{Hg}$ emission line can be identified.

In LIBS, the area below the emission peak of the spectrum is usually correlated with the concentration of a specific element. Using an appropriate model, it is possible to obtain a calibration curve that improves the Pearson's linear correlation coefficient to get values close to 1 . The validation model used in this work is based on the leave-one-out cross validation process, which consists in extracting one sample from all samples and using the remaining ones to build the calibration model. The excluded sample (called unknown data) is then used to test the quantification efficiency of the calibration curve obtained by converting the peak area in a predicted $\mathrm{Hg}$ concentration. In this way, the peak area and the calibration curve are used to obtain the $\mathrm{Hg}$ concentration predicted by the model. This value is then compared to the value of $\mathrm{Hg}$ in the leachate measured by the reference technique, which, in turn, generates the prediction error value. The process is then repeated for all samples so that an average prediction error can be recorded. This value can be considered a direct measure of the elemental quantification efficiency of the DP LIBS technique for the determination of $\mathrm{Hg}$ in the leachate.

\section{RESULTS AND DISCUSSION}

Figure 2(a) shows a typical LIBS spectrum of the sample containing $1000 \mathrm{mg} \mathrm{Kg}^{-1} \mathrm{Hg}$ acquired by the DP LIBS in the region $175-330 \mathrm{~nm}$. According to the literature [22,24,25,26], the most used emission line for $\mathrm{Hg}$ analysis by LIBS is the atomic $\mathrm{Hg}$ (I) line at $253.65 \mathrm{~nm}$, which is shown in the expansion in Fig. 2(b). This emission line of $\mathrm{Hg}$ does not allow us to build an acceptable quantification model because of the poor correlation resulting between this $\mathrm{Hg}$ line and the known $\mathrm{Hg}$ concentration, which is reasonably caused by interferences of the very close Fe II and Fe I lines. Any attempt to eliminate this interference was unsuccessful because of the high amount of $\mathrm{Fe}$ in the samples, of the order of $200 \mathrm{mg} \mathrm{Kg}^{-1}$.

In order to find a better $\mathrm{Hg}$ emission line to be used in the quantification model, the "peak finding" algorithm was applied to the spectra by which each pixel was compared with the actual $\mathrm{Hg}$ concentration in the samples. The correlation graph obtained (Fig. 3) indicated that the highest correlation value $(R=0.65)$ was featured by the $194.163 \mathrm{~nm}$ pixel [Fig. 1(c)], which corresponds to the ionic $\mathrm{Hg}$ emission line ( $\mathrm{Hg}$ II,
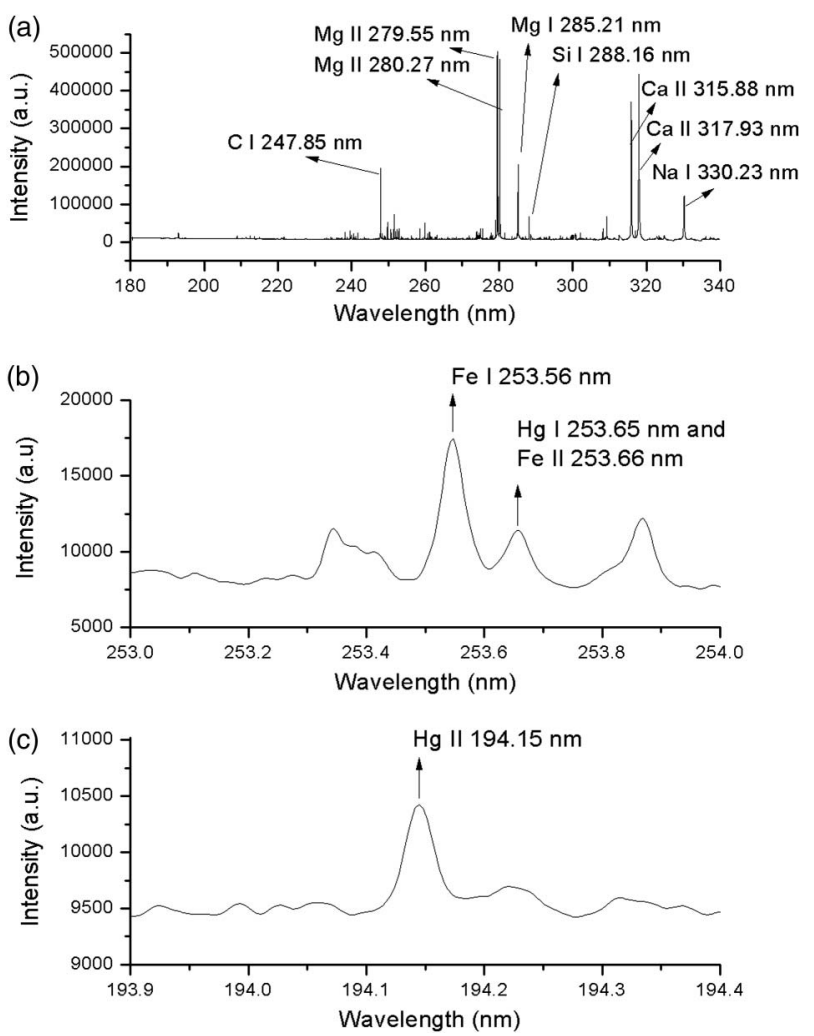

Fig. 2. (a) LIBS spectrum of the sample containing $1000 \mathrm{mg} \mathrm{Kg}^{-1}$ $\mathrm{Hg}$ acquired by DP LIBS in the region 175-330 nm; (b) expansion of the spectrum in the region 253-254 $\mathrm{nm}$ showing the Fe I $(253.56 \mathrm{~nm}), \mathrm{Hg}$ I $(253.65 \mathrm{~nm})$, and Fe II $(253.66 \mathrm{~nm})$ emission lines; (c) expansion of the region 193.9-194.4 nm showing the $\mathrm{Hg}$ II $(194.163 \mathrm{~nm})$ emission line.

$\left.5 \mathrm{~d}^{10} 6 \mathrm{~s}\left({ }^{2} \mathrm{~S}_{1 / 2}\right) \rightarrow 5 \mathrm{~d}^{10} 6 \mathrm{p}\left({ }^{2} \mathrm{P}_{1 / 2}\right), \quad A=7.5 \times 10^{8} \mathrm{~s}^{-1}\right)$ according to the NIST database [27]. It is important to note that when using SP LIBS measurements it was not possible to observe the $\mathrm{Hg}$ II emission line at $194.163 \mathrm{~nm}$ in all samples, and at $253.65 \mathrm{~nm}$ no signal was observed below an $\mathrm{Hg}$ concentration of $500 \mathrm{mg} \mathrm{Kg}^{-1}$. The inset graphic in Fig. 3 shows the poor correlation resulting between the atomic $\mathrm{Hg}(\mathrm{I})$ line at $253.65 \mathrm{~nm}$ and the known $\mathrm{Hg}$ concentration.

The correlation of the Hg II $194.163 \mathrm{~nm}$ emission line was surrounded by a background noise region (Fig. 3) that can be due to a combination of factors, which include the low number of samples analyzed (10 in total), the fluctuation of the DPLIBS system, and the low intensity of the $\mathrm{Hg}$ II emission line. Thus, a Gaussian function was fitted to the emission line (Fig. 4) in order to extract the information from it by applying a baseline correction to eliminate the non-negligible background fluctuation and improve the correlation between the LIBS signal and $\mathrm{Hg}$ concentration in the matrix. The LIBS signal area was corrected on the basis of the average of a background region selected nearby the emission line using the following equation:

$$
A=A_{L}-\alpha * A_{B},
$$

where $A_{L}$ is the area extracted from the fitted Gaussian curve in Fig. 3, $A_{B}$ is the averaged background and $\alpha$ is an optimization 


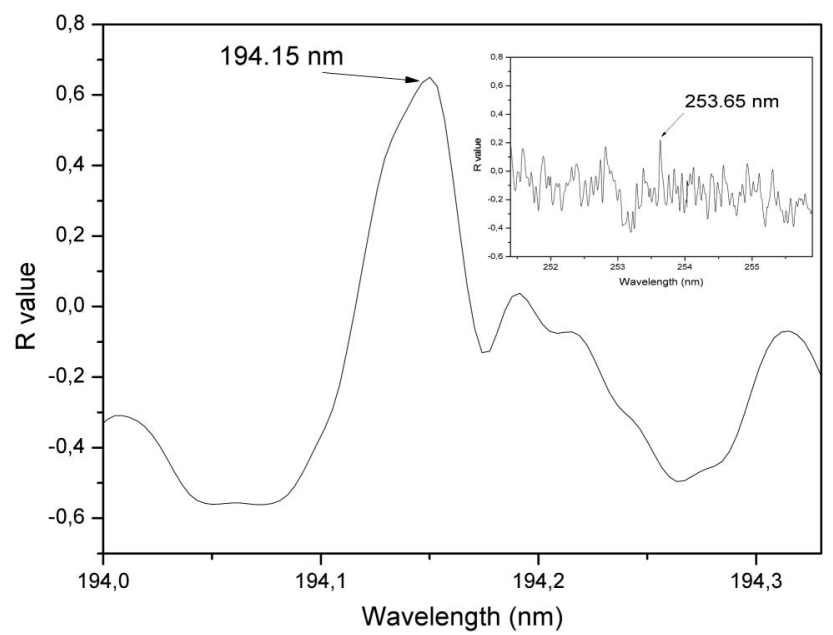

Fig. 3. Correlation graph for $\mathrm{Hg}$. Each pixel was linearly correlated with the $\mathrm{Hg}$ content in the samples.

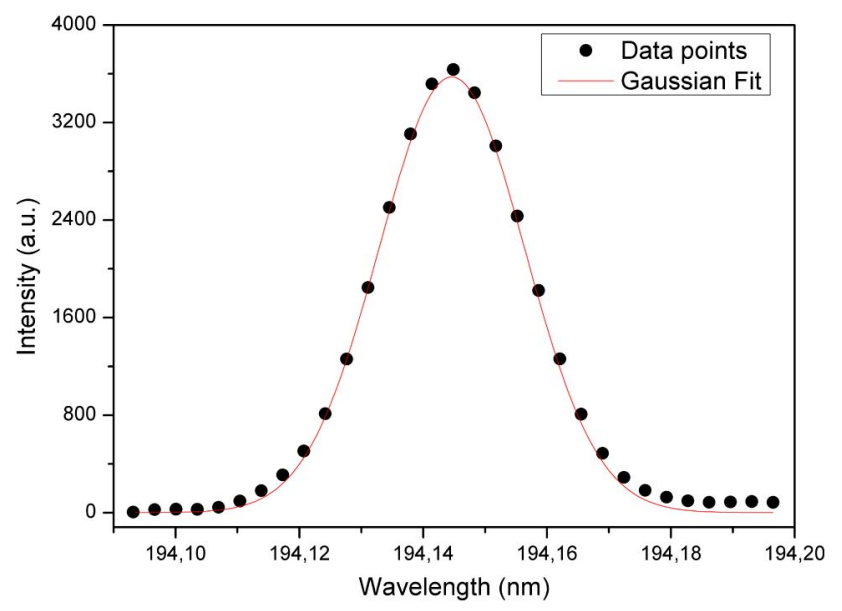

Fig. 4. Gaussian function fitting data of the $\mathrm{Hg}$ II peak emission line in the sample containing $1000 \mathrm{mg} \mathrm{Kg}^{-1} \mathrm{Hg}$.

factor. The $\alpha$ parameter was optimized by performing a linear fitting for the best Person's coefficient in the calibration model. To evaluate this model the value of A was linearly correlated with the $\mathrm{Hg}$ concentration in the landfill leachate matrix. The model details can be found in a previous paper [13]. Figures 5(a) and 5(b) show that a much better correlation $(R=0.98)$ could be obtained when the normalization process using Eq. (1) was applied to LIBS spectra to correct physical matrix effects and small fluctuations, with respect to the correlation obtained when no correction was applied $(R=0.82)$.

The LOD is a measure of the lowest concentration of the element that can be detected by a technique and is calculated according to the following equation [28]:

$$
\mathrm{LOD}=3.3 \frac{\sigma}{b}
$$

where $\sigma$ is the standard deviation of the background for the lowest concentrate sample and $b$ is the slope of the calibration
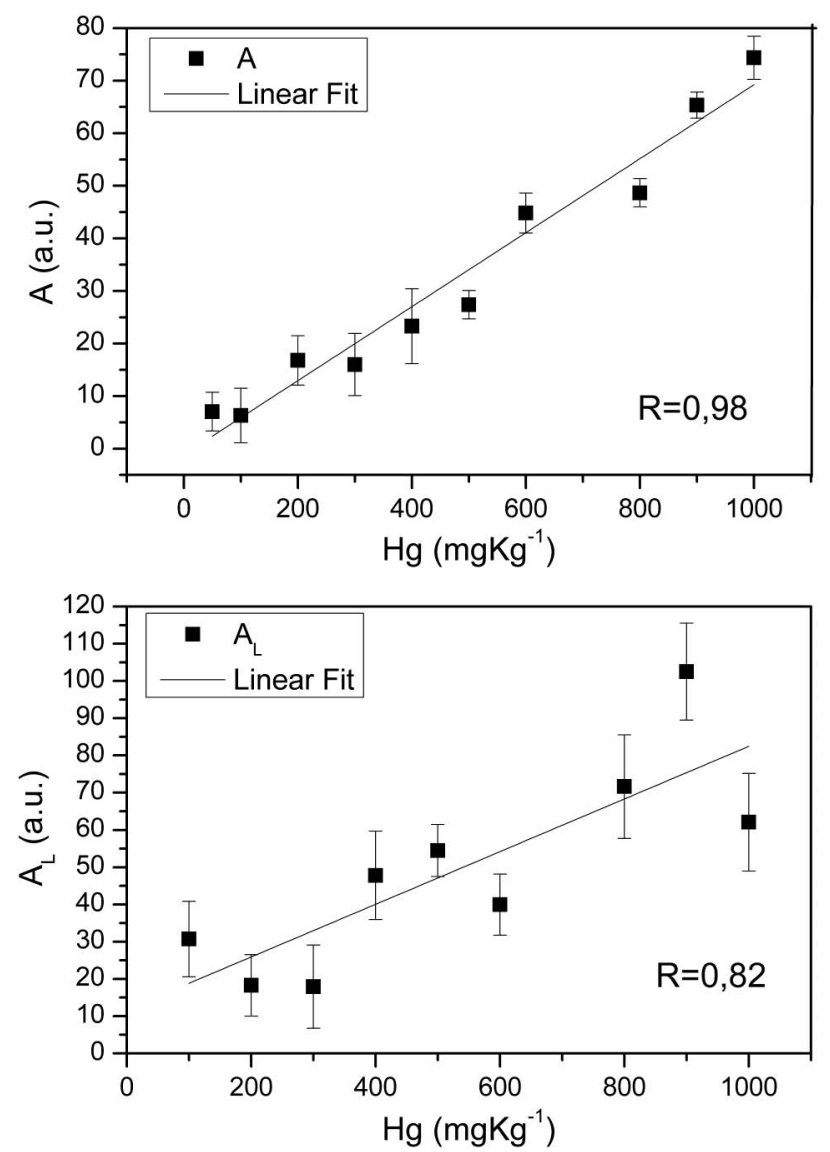

Fig. 5. Calibration curve for $\mathrm{Hg}$ concentration in landfill leachate using (a) the signal area corrected by Eq. (1), A and (b) the non corrected signal area $A_{L}$.

curve. In this experiment, $\sigma$ was calculated using the averaged background intensity of the pixels close to the chosen emission line peak and $b$ was extracted from the slope of the calibration model using all samples. The LOD of Hg II at $194.15 \mathrm{~nm}$ was calculated to be $76 \mathrm{mg} \mathrm{Kg}^{-1}$, which is about six times lower than that obtained in previous studies on solid samples such

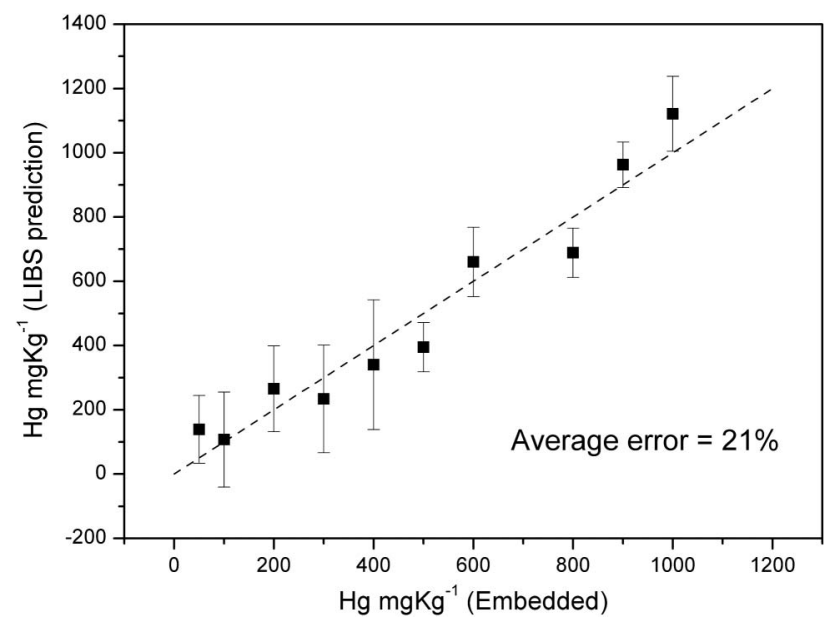

Fig. 6. Leave-one-out cross validation graph. 
as soils [19]. The improvement of the detection sensitivity can be ascribed mainly to the use of the DP LIBS, which also allowed us to use the $194.163 \mathrm{~nm} \mathrm{Hg}$ emission line. However, even if this line is relatively weak compared to the $\mathrm{Hg}$ emission line commonly used in other works, the advantage is that this line does not suffer from interference by other elements, allowing the use of a simplified correction model.

Figure 6 shows the result of the leave-one-out cross validation process described in Section 2.C. The average mean error calculated was $21 \%$, which is a value adequate for $\mathrm{Hg}$ quantification in landfill leachates.

\section{CONCLUSIONS}

This work reports for the first time the performance of DP LIBS in the analysis of the toxic metal $\mathrm{Hg}$ in landfill leachates. The DP LIBS technique allowed us to detect and use the $194.163 \mathrm{~nm} \mathrm{Hg}$ II emission line to build a quantification model for $\mathrm{Hg}$. The use of this emission line appears to be a good alternative to eliminate interference by others elements, that is, the Fe I $253.56 \mathrm{~nm}$ and Fe II $253.66 \mathrm{~nm}$ peaks that have an emission line very close to $\mathrm{Hg}$ I $(253.65 \mathrm{~nm})$. Because of this interference, it was not possible to construct a reasonable correlation model using $\mathrm{Hg} \mathrm{I}$ at $253.65 \mathrm{~nm}$. Differently, the emission line of $\mathrm{Hg}$ II at $194.163 \mathrm{~nm}$ under optimized experimental conditions allowed us to build a model that improved from $R=0.82$ to $R=0.98$ the linear correlation between LIBS data and the actual $\mathrm{Hg}$ concentrations, with a consequent reduction of the mean error to $21 \%$ with a LOD of $76 \mathrm{mg} \mathrm{Kg}^{-1}$.

In conclusion, LIBS is confirmed to represent a promising alternative to the traditional analytical techniques that require sample preparation and the use of chemical reagents for the measurement of trace $\mathrm{Hg}$ in landfill leachates. Further, it can be reasonably expected that LIBS instrumentation implementations, such as the resonant excitation and the discharge excitation, would improve further the limits of detection and quantification offered by LIBS.

Funding. Fundação de Amparo à Pesquisa do Estado de São Paulo (FAPESP) (2012/24349-0, 2013/07276-1); Empresa Brasileira de Pesquisa Agropecuária (EMBRAPA); Conselho Nacional de Desenvolvimento Científico e Tecnológico (CNPq) (461743/2014-0).

\section{REFERENCES}

1. P. Kjeldsen, M. A. Barlaz, A. P. Rooker, A. Baun, A. Ledin, and T. H. Christensen, "Present and long-term composition of MSW landfill leachate: a review," Crit. Rev. Environ. Sci. Technol. 32, 297-336 (2002).

2. F. X. Han, A. Banin, Y. Su, D. L. Monts, M. J. Plodinec, W. L. Kingery, and G. E. Triplett, "Industrial age anthropogenic inputs of heavy metals into the pedosphere," Naturwissenschaften 89, 497-504 (2002).

3. F. X. Han, Y. Su, D. L. Monts, M. J. Plodinec, A. Banin, and G. E. Triplett, "Assessment of global industrial-age anthropogenic arsenic contamination," Naturwissenschaften 90, 395-401 (2003).

4. D. W. Boening, "Ecological effects, transport, and fate of mercury: a general review," Chemosphere 40, 1335-1351 (2000).
5. T. H. Christensen, P. Kjeldsen, P. L. Bjerg, D. L. Jensen, J. B. Christensen, A. Baun, H. J. Albrechtsen, and G. Heron, "Biogeochemistry of landfill leachate plusem," Appl. Geochem. 16, 659-718 (2001)

6. D. Kulikowska and E. Klimiuk, "The effect of landfill age on municipal leachate composition," Bioresour. Technol. 99, 5981-5985 (2008).

7. V. Tsarpali, M. Kamilari, and S. Dailianis, "Seasonal alterations of landfill leachate composition and toxic potency in semi-arid regions," J. Hazard. Mater. 233, 163-171 (2012).

8. G. Gauglitz and T. Vo-Dinh, Handbook of Spectroscopy (Wiley, 2003).

9. B. Beckhoff, B. Kanngießer, N. Langhoff, R. Wedell, and H. Wolff, Handbook of Practical X-Ray Fluorescence Analysis (Springer, 2006).

10. A. Argyraki, M. H. Ramsey, and P. J. Potts, "Evaluation of portable $X$-ray fluorescence instrumentation for in situ measurements of lead on contaminated land," Analyst 122, 743-749 (1997).

11. M. Baudelet and B. W. Smith, "The first years of laser-induced breakdown spectroscopy," J. Anal. At. Spectrom. 28, 624-629 (2013).

12. G. S. Senesi, M. Dell'Aglio, R. Gaudiuso, A. DeGiacomo, C. Zaccone, O. DePascale, T. M. Miano, and M. Capitelli, "Heavy metal concentrations in soils as determined by laser-induced breakdown spectroscopy (LIBS), with special emphasis on chromium," Environ. Res. 109, 413-420 (2009).

13. B. S. Marangoni, K. S. G. Silva, G. Nicolodelli, G. S. Senesi, J. S. Cabral, P. R. Villas-Boas, C. S. Silva, P. C. Teixeira, A. R. A Noqueira, V. M. Benites, and D. M. B. P. Milori, "Phosphorus quantification in fertilizers using laser induced breakdown spectroscopy (LIBS): a methodology of analysis to correct physical matrix effects," Anal. Methods 8, 78-82 (2016).

14. G. Nicolodelli, B. S. Marangoni, J. D. S. Cabral, P. R. Villas Boas, G. S. Senesi, C. H. Santos, R. A. Romano, A. Segnini, Y. Lucas, C. R. Montes, and D. M. B. P. Milori, "Quantification of total carbon in soil using laser-induced breakdown spectroscopy: a method to correct interference lines," Appl. Opt. 53, 2170-2176 (2014).

15. G. Nicolodelli, G. S. Senesi, R. A. Romano, I. L. O. Perazzoli, and D. M. B. P. Milori, "Signal enhancement in collinear double-pulse laser-induced breakdown spectroscopy applied to different soils," Spectrochim. Acta B 111, 23-29 (2015).

16. G. Nicolodelli, G. S. Senesi, I. L. O. Perazzoli, B. S. Marangoni, V. M. Benites, and D. M. B. P. Milori, "Double pulse laser induced breakdown spectroscopy: a potential tool for the analysis of contaminants and macro/micronutrients in organic mineral fertilizers," Sci. Total Environ. 565, 1116-1123 (2016).

17. S. Palanco, C. López-Moreno, and J. J. Laserna, "Design, construction and assessment of a field-deployable laser-induced breakdown spectrometer for remote elemental sensing," Spectrochim. Acta B Atom. Spectros. 61, 88-95 (2006).

18. S. Maurice, R. Wiens, M. Saccoccio, B. Barraclough, O. Gasnault, O. Forni, N. Mangold, D. Baratoux, S. Bender, and G. Berger, "The ChemCam instrument suite on the Mars Science Laboratory (MSL) rover: Science objectives and mast unit description," Space Sci. Rev. 170, 95-166 (2012).

19. P. K. Srungaram, K. K. Ayyalasomayajula, F. Yu-Yueh, and J. P. Singh, "Comparison of laser induced breakdown spectroscopy and spark induced breakdown spectroscopy for determination of mercury in soils," Spectrochim. Acta B Atom. Spectros. 87, 108-113 (2013).

20. H. Sobral, R. Sanginés, and A. Trujillo-Vázquez, "Detection of trace elements in ice and water by laser-induced breakdown spectroscopy," Spectrochim. Acta B Atom. Spectros. 78, 62-66 (2012).

21. X. Fang and S. Rafi Ahmad, "Sample presentation considerations in laser-induced breakdown spectroscopy in aqueous solution," Appl. Spectrosc. 61, 1021-1024 (2007).

22. P. Zheng, H. Liu, J. Wang, M. Shi, X. Wang, B. Zhang, and R. Yang, "Online mercury determination by laser-induced breakdown spectroscopy with the assistance of solution cathode glow discharge," J. Anal. At. Spectrom. 30, 867-874 (2007).

23. D. W. Hahn and N. Omenetto, "Laser-induced breakdown spectroscopy (LIBS), part II: review of instrumental and methodological approaches to material analysis and applications to different fields," Appl. Spectrosc. 66, 347-419 (2012). 
24. C. Lazzari, M. De Rosa, S. Rastelli, A. Ciucci, V. Palleschi, and A. Salvetti, "Detection of mercury in air by time-resolved laser-induced breakdown spectroscopy technique," Laser Part. Beams 12, 525-530 (1994).

25. W. Tawfik and A. Saafan, "Quantitative analysis of mercury in silver dental amalgam alloy using laser induced breakdown spectroscopy with a portable Echelle spectrometer," Int. J. Pure Appl. Phys. 3, 195-203 (2006).
26. R. L. Gleason and D. W. Hahn, "The effects of oxygen on the detection of mercury using laser-induced breakdown spectroscopy," Spectrochim. Acta B Atom. Spectros. 56, 419-430 (2001).

27. http://www.nist.gov/.

28. L. A. Currie, "Limits for qualitative detection and quantitative determination. Application to radiochemistry," Anal. Chem. 40, 586-593 (1968). 